\title{
MESHING SIMULATION AND STRENGTH CALCULATION OF A CARBURIZED GEAR PAIR
}

\author{
Li, X. Y.*; Zhang, Q. X.*; Wang, N. N. ; Zeng, Q. L. ${ }^{*} \&$ Hidenori, K. ${ }^{* *}$ \\ * College of Mechanical and Electronic Engineering, Shandong University of Science and Technology, \\ Qingdao, 266590, China \\ ** PSC Co., Ltd. Kanagawa-ken, 225-0013, Japan \\ E-Mail: lixueyi07@tsinghua.org.cn
}

\begin{abstract}
The material in the carburized layer of a carburized gear is nonlinear. However, no systematic theory and method is available to analyse the strength of nonlinear materials; thus, calculating the exact strength of carburized gears is difficult. The traditional method of calculating the strength of carburized gears considered the material as uniform, which is susceptible to make errors. To address this problem, a hierarchical simulation method was proposed to calculate the strength of carburized gears. The strength calculation principle of carburized gears was first analysed. Then, a solid modelling method of carburized gears was presented based on the extraction technology of the layered homogeneous material. Finally, the meshing process of carburized gears was simulated, and the distribution and variation laws of the root, contact, and shear stresses during the meshing process were determined accurately. Results show that the shear stress of carburized gears initially increases and then decreases along with depth direction, and the maximum value appears in the surface below. However, the shear stress of non-carburized gears decreases linearly. The equivalent stress of the two kinds of gears decreases linearly with depth direction, whereas the decreasing amplitude of the carburized gears is larger than that of the non-carburized gears. A significant error in the calculation of the strength of carburized gears can be clearly observed using the traditional method. By selecting the appropriate parameters, the method proposed in this study can be used to simulate the meshing process of the carburized gear pair and calculate its strength accurately.

(Received in August 2016, accepted in December 2016. This paper was with the authors 1 month for 1 revision.)
\end{abstract}

Key Words: Carburized Cylindrical Gears, Strength Analysis, Modelling, Transient Simulation Analysis

\section{INTRODUCTION}

Gear transmission is an important mechanical transmission mechanism and is widely used in various industrial fields [1]. Carburization is important in ensuring wear resistance and bending resistance during high speed and overloading [2,3]. The carbon concentration at each point in the gear surface and below becomes different after carburization. Thus, a carburized gear is considered a heterogeneous material, and the elastic modulus decreases gradually from the carburized surface. When a carburized gear is loaded, the equivalent and shear stresses at different carburized depths become nonlinear. Therefore, the strength of carburized gears should be calculated according to the heterogeneous materials. However, no mature method has accurately calculated the strength of carburized gears to date. The majority of the existing gear design methods consider carburized gears as homogeneous materials without considering the nonlinearity of the material, which leads to a large error in strength calculation. Testing the strength of the parts after design completion is necessary to ensure the reliability of the design [4]; however, this process is costly and time-consuming. Finite element method (FEM) can be used to calculate the strength of heterogeneous materials; however, the accuracy of its calculation depends on the correctness of finite element modelling. In recent years, several scholars have studied the method of calculating the strength of carburized gears using FEM. However, establishing a finite element model of carburized gears is yet to be accomplished 
[5]. The stress distribution and variation law of carburized gears at different carburizing depths cannot be obtained accurately using the traditional calculation method. The calculation of gear strength is the basis of gear design and optimization. Therefore, establishing an effective finite element model of the carburized gear and analysing its strength accurately are of great theoretical and practical significance.

\section{STATE OF THE ART}

Most current studies on carburized gears are limited to the theory of heat treatment and strength analysis for fatigue failure, and rarely involve the precise modelling and strength analysis of carburized gears. Li et al. [6] studied several forms of failure of carburized gears and performed simulation analysis based on ANSYS. However, the modelling process and performance analysis of carburized gears were not described in detail. Some scholars $[7,8]$ observed the microstructure properties of carburized gears to find the initiation and extension of damage; however, this method is only applicable to some specific materials and conditions. Yamanaka et al. [9] used four different manufacturing methods for spur gears and found that forging is the best way to increase bending stress of carburized gears. Zwolak and Palczak [10] studied the influence of two treatment methods on contact strength of gears by analysing the characteristic of surface layer, which did not involve bending and shear stresses. Some scholars $[11,12]$ also studied the fatigue crack and pitting failure of carburized gears through experiments. However, these methods cannot meet the requirements of comprehensive analysis of carburized gear strength.

Some scholars performed numerical simulation on carburizing heat treatment process of gears based on FEM. Kim and Bae [13] analysed the gear deformation in different quenching temperatures during carburizing-quenching simulation and provided process parameters for actual production. Decroos and Seefeldt [14] established a half-gear tooth finite element model to simulate the process of carburization and quenching, and predicted the gear stress and strain after this process. Li et al. [15] simulated various residual stresses during carburization and quenching. In the literature [16-19], the carburizing heat treatment of other gear types, including gear ring, was simulated similarly. However, these studies did not perform simulation analysis on carburized gears during their actual work process.

The depth of a carburized layer is an important parameter in the design of carburized gears. Several computing methods for the case depth of carburized gears were proposed in some studies [20,21], which only involved a few process parameters and did not discuss the strength of carburized gears.

The majority of existing studies discussed the simulation of the heat treatment process, tested the strength, and performed failure analysis based on experiment. In this study, the use of multilayer homogeneous layers replaced the carburizing part, compensating the limitations of the existing technology on the modelling and strength analysis of carburized cylindrical gears.

The present study is organized as follows. Section 3 introduces three kinds of strength analyses in theory, and modelling of carburized layers and gear pair. Section 4 considers a helical gear pair for simulation and compares it with the modelling without stratification. Section 5 presents the conclusions.

\section{METHODOLOGY}

\subsection{Strength analysis of carburized cylindrical gears}

The pitting failure of gears is caused by the high-contact stress between driving and driven gear teeth in the process of cycle rotation. The contact of the two meshing teeth is considered 
as two elastic compressed cylinders in the traditional method. According to Hertz theory, the contact fatigue strength formula [22] of cylindrical gears is as follows:

$$
\sigma_{H}=\sqrt{\frac{2 K_{H} T_{1}}{\Phi_{d} d_{1}^{3}} \cdot \frac{u \pm 1}{u}} Z_{H} Z_{E} Z_{\varepsilon}
$$

where $K_{H}$ is the load factor used to calculate contact fatigue strength; $T_{1}$ is the torque of driving gear; $\Phi_{d}$ is the face width coefficient; $d_{1}$ is the reference diameter of the driving gear; $u$ is the transmission ratio; $Z_{H}$ is the regional coefficient; $Z_{\varepsilon}$ is the contact ratio factor used to calculate contact stress; $Z_{E}$ is the influence coefficient of elastic, $Z_{E}=\sqrt{\frac{1}{\pi\left[\left(\frac{1-\mu_{1}^{2}}{E_{1}}\right)+\left(\frac{1-\mu_{2}^{2}}{E_{2}}\right)\right]}} ; \mu_{1}$ and $\mu_{2}$ are the Poisson ratios of the two gears; $E_{1}$ and $E_{2}$ are the elastic moduli of the two gears.

The contact stress is closely related to the elastic modulus, which changes with the various carbon concentrations for carburized gears. Calculating contact stress using Eq. (1) will cause error and cannot reflect the actual contact stress accurately.

Moreover, bending stress exists on the root of the gear tooth. When the gear pair is meshed in the crest, two pairs of gear teeth are in the meshing state, which bear the load simultaneously; thus, the maximum bending stress does not appear in this meshing position. When the load is applied on the top point of one pair of the gear teeth, the maximum bending stress appears in the tooth root, and the crack is produced easily. The large rigidity causes the gears to be considered as a cantilever beam, and ignoring the influence of rub. The normal force $F_{n}$ is applied to the crest, in which $\alpha_{n}$ is the pressure angle, as shown in Fig. 1. The bending stress [22] in the dangerous section is expressed as follows:

$$
\sigma_{F}=\frac{2 K_{F} T_{1} Y_{F a} Y_{s a} Y_{\varepsilon}}{\Phi_{d} m^{3} z^{2}}
$$

where $K_{F}$ is the load factor used to calculate bending fatigue strength, $Y_{F a}$ is the tooth form factor, $Y_{s a}$ is the stress correction coefficient, $Y_{\varepsilon}$ is the contact ratio factor used to calculate the bending stress, $m$ is the gear module, and $z$ is the number of teeth.

Most of the coefficients in Eq. (2) are acquired by experience, which makes the calculation result an approximate. Hence, calculating the bending stress of carburized gears using Eq. (2) is not reasonable.

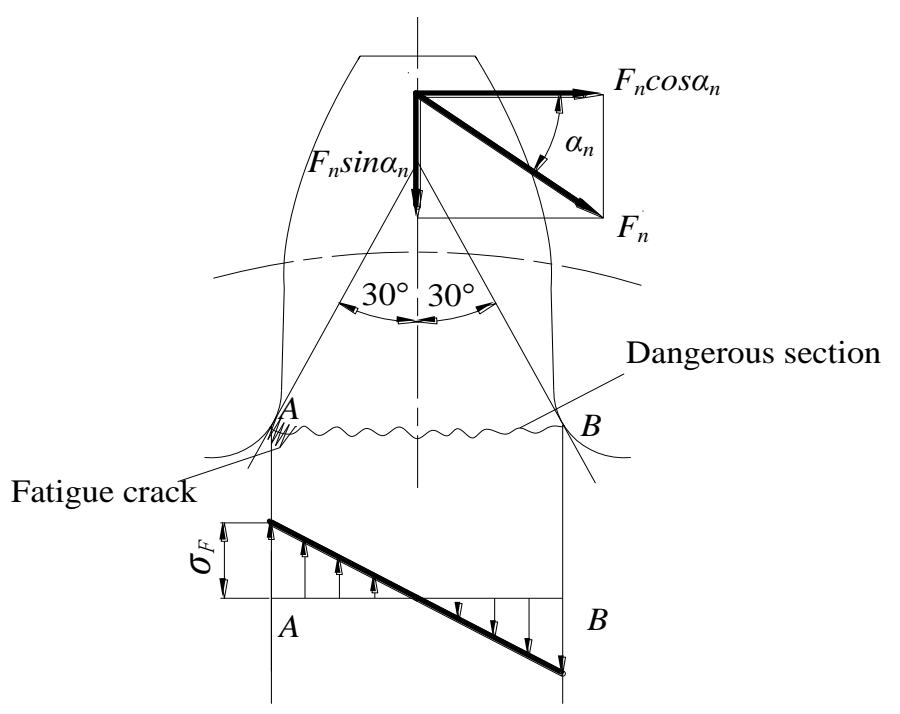

Figure 1: Bending stress of the root. 
Moreover, the carburized layer involves alternating shear stress during gear meshing. If the shear stress exceeds the ultimate strength of the material, then spalling would be produced, which generally appears in the range of the hardness layer in the form of a crack.

By circulating the positive pressure of the gear, pulsating cyclic shear stress $\tau_{y z}$ and symmetrical cyclic shear stress $\tau$ are generated in the carburized layers. By ignoring the friction, the maximum value $\tau_{y z \max }$ is produced below the surface $0.78 q$ and the maximum value $\tau_{\max }$ appears below the surface $0.5 q$, where $q$ is the half-width of the contact zone for the two cylinders. The half-width of the contact zone can be obtained according to elastic mechanics, which is presented as follows:

$$
q=\sqrt{\frac{4 F_{n}}{\pi L}\left(\frac{1-\mu_{1}^{2}}{E_{1}}+\frac{1-\mu_{2}^{2}}{E_{2}}\right) \rho_{\Sigma}}
$$

where $L$ is the contact length of the gear; $\rho_{\Sigma}$ is the integrated curvature radius of tooth profile, $\rho_{\Sigma}=\frac{\rho_{1} \rho_{2}}{\rho_{1} \pm \rho_{2}}$; and $\rho_{1}$ and $\rho_{2}$ are the curvature radii at the contact point.

The crack is caused by the symmetrical cyclic shear stress $\tau$ rather than the pulsating shear stress $\tau_{y z}$. When the shear stress $\tau$ exceeds the plastic deformation resistance of the material, the crack that originates from the plastic deformation zone will cause shallow spalling. On the basis of the third strength theory, the maximum shear stress value [23] on the principal shear stress plane can be expressed as follows:

$$
\tau_{\max }=\frac{1}{2}\left(\sigma_{1}-\sigma_{3}\right)
$$

where $\sigma_{1}$ and $\sigma_{3}$ are the maximum and minimum algebraic values of the principal stress, respectively.

The junction between the hardness layer and the heart is a weak link. To avoid the production of spalling by the transition layer, the ratio of the shear stress in the transition zone and shear strength resistance $[\tau]$ should not be larger than 0.55 , as expressed below:

$$
\varepsilon=\frac{\tau_{\max }}{[\tau]} \leqslant 0.55
$$

\subsection{Modelling of carburized layers}

According to the principle of gear structure, the tooth profile of cylindrical gears consists of involute curve, tooth root transition curve, tooth root arc, and addendum arc. The equation of the involute curve in Cartesian coordinates is as follows:

$$
\left\{\begin{array}{l}
x_{d}=r_{b}(\sin \lambda-\lambda \cos \lambda) \\
y_{d}=r_{b}(\cos \lambda+\lambda \sin \lambda)
\end{array}\right.
$$

where $x_{d}$ and $y_{d}$ are the abscissa and the ordinate of the point on the involute, respectively; $r_{b}$ is the basic circle radius, and $\lambda=\tan \alpha_{k}$, where $\alpha_{k}$ is the pressure angle of the point on the involute.

Tooth root transition curve is formed by the rounded corners of the tool tip during gear machining. Various cutting tools and processing methods can change the tooth root transition curve. This study adopts hobbing method to manufacture the gears using rack-shaped cutting tools. The tooth root transition curves are the equidistant curve of the extended involute. In the Cartesian coordinate system, the parametric equation [24] of the tooth root transition curve is as follows: 


$$
\left\{\begin{array}{l}
x_{g}=r \sin \varphi-\left(\frac{a_{1}}{\sin \alpha^{\prime}}+r_{\rho}\right) \cos \left(\alpha^{\prime}-\varphi\right) \\
y_{g}=r \cos \varphi-\left(\frac{a_{1}}{\sin \alpha^{\prime}}+r_{\rho}\right) \sin \left(\alpha^{\prime}-\varphi\right)
\end{array}\right.
$$

where $\alpha \leq \alpha^{\prime} \leq 90^{\circ}, \varphi=\left(a_{1} \cot \alpha^{\prime}+b\right) / r$, and $a_{1}=a-x m$.

In Eq. (7), $x_{g}$ and $y_{g}$ are the abscissa and ordinate of the point on the transition curve, respectively; $r$ is the pitch radius of the machining gear; $\varphi$ is the angle between the connection of the centre and pitch points and the centreline of the machining gear; $\alpha^{\prime}$ is the angle between the common normal of the contact point between the tool radius and the transition curve, and the tool processing pitch line; $\alpha$ is the pressure angle of the reference circle; $a$ is the distance from the centre of the top corner of the cutter to the middle line; $b$ is the distance from the centre of the top corner of the cutter to the centreline of the cutter space width; $r_{\rho}$ is the top corner radius of the cutter; and $x$ is the modification coefficient.

A series of tooth profile points can be acquired using the equation of profile curve. The density of the point on the tooth profile is adjusted adaptively according to curvature to ensure the accuracy of the modelling. After obtaining the profile points completely, they are arranged in the same number of layers in the direction of tooth width along the spiral, to obtain the point matrix of tooth profile surface. These points are sorted and integrated by ranks to acquire the complete point matrix $\boldsymbol{P}_{i, j}(i=0,1,2, \ldots, m ; j=0,1,2, \ldots, n)$ of the tooth profile surface, as shown in Fig. 2. The equation of bicubic B-spline curve [25] is as follows:

$$
P(u, v)=\sum_{i=0}^{m+2} \sum_{j=0}^{n+2} V_{i, j} N_{i, 3}(u) N_{j, 3}(v)
$$

where $\boldsymbol{V}_{i, j}(i=0,1,2, \ldots, m+2 ; j=0,1,2, \ldots, n+2)$ is the control point matrix of the surface, and $\boldsymbol{N}_{i, 3}(u)$ and $\boldsymbol{N}_{j, 3}(v)$ are the cubic B-spline basis functions along $u$ and $v$ directions, respectively. The inversion of the bicubic B-spline surface obtains the control point matrix $\boldsymbol{V}_{i, j}$ and acquires the complete tooth profile surface, which is the surface of the carburized gear tooth, as shown in Fig. 2.

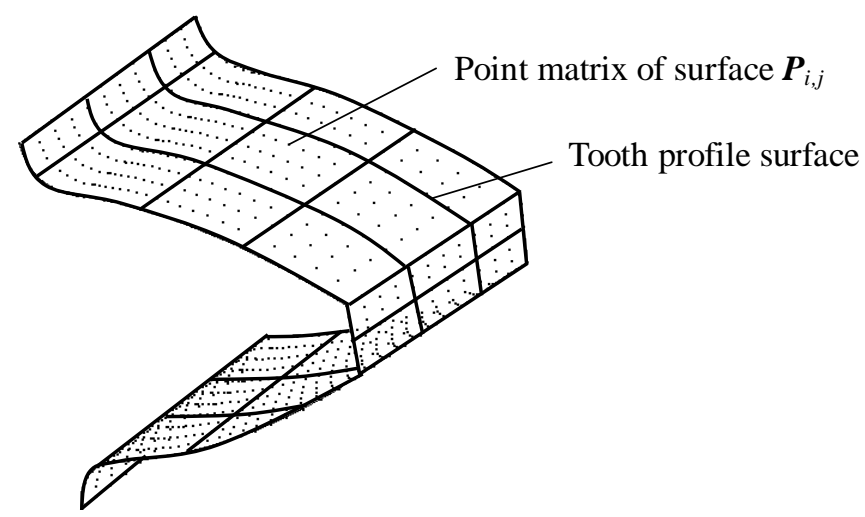

Figure 2: Point matrix and tooth profile surface.

The carburized layers are built after obtaining the tooth profile surface. In this study, multilayer homogeneous carburized layers are used to simulate the approximate model of the carburized gear. The number of homogeneous layers for carburization corresponds to the accuracy of the model, which increases the difficulty of modelling and calculation. Given the modelling accuracy and computational efficiency, the total number of homogeneous layers is usually from three to six, and the specific number is determined by the depth of carburizing. The carburized part of gear is composed of effective hardness layer and transition layer. The depth of carburizing is $t$, which is divided into $s$ layers. The thickness of the effective 
hardness layer is $t_{a}$, which is divided into $f$ layers. The transition layer thickness is $t_{b}$, which is divided into $h$ layers. The thickness of the carburized layer from the surface to the inner layer is $t_{i}(i=1,2, \ldots, s)$, and their relationship can be expressed as follows:

$$
\left\{\begin{array}{l}
t=t_{a}+t_{b} \\
t_{b} \approx 0.54 t_{a} \\
s=f+h \\
t_{1}=\frac{t_{a}}{f+1} \\
t_{i}=\frac{t_{a}-t_{1}}{f-1}(i=2, \cdots, f) \\
t_{i}=\frac{t_{b}}{h}(i=f+1, \cdots, s)
\end{array}\right.
$$

The tangent vectors in $u$ and $v$ directions at each point on the surface can be calculated using Eq. (8). The normal vector at each point is the cross product of two tangent vectors. The unit normal vector $\boldsymbol{n}$ can be obtained by dividing the size of the crossed module. Normal offset point $\boldsymbol{P}_{i, j}^{\prime}$ can be obtained by offsetting point $t_{i}$ distance reversely along the unit normal vector, as shown in Fig. 3 . The coordinates of $\boldsymbol{P}_{i, j}^{\prime}$ can be acquired as follows:

$$
\boldsymbol{P}_{i, j}^{\prime}=\boldsymbol{P}_{i, j}-t_{i} \boldsymbol{n}(i=0,1,2, \ldots, m ; j=0,1,2, \ldots, n)
$$

The point matrix of the tooth profile offsets $t_{1}$ distance along the normal direction to obtain the offset point matrix and fits them to acquire the first equidistant offset surface. The first equidistant offset surface with the tooth profile surface surrounds the first homogeneous carburized layer. Offsetting inwardly the first offset surface, which is considered as the base surface, establishes the second equidistant surface. The second equidistant surface with the first offset surface then surrounds the second homogeneous carburized layer. As shown in Fig. 3 , the remaining layers can be obtained orderly by repeating the above process.

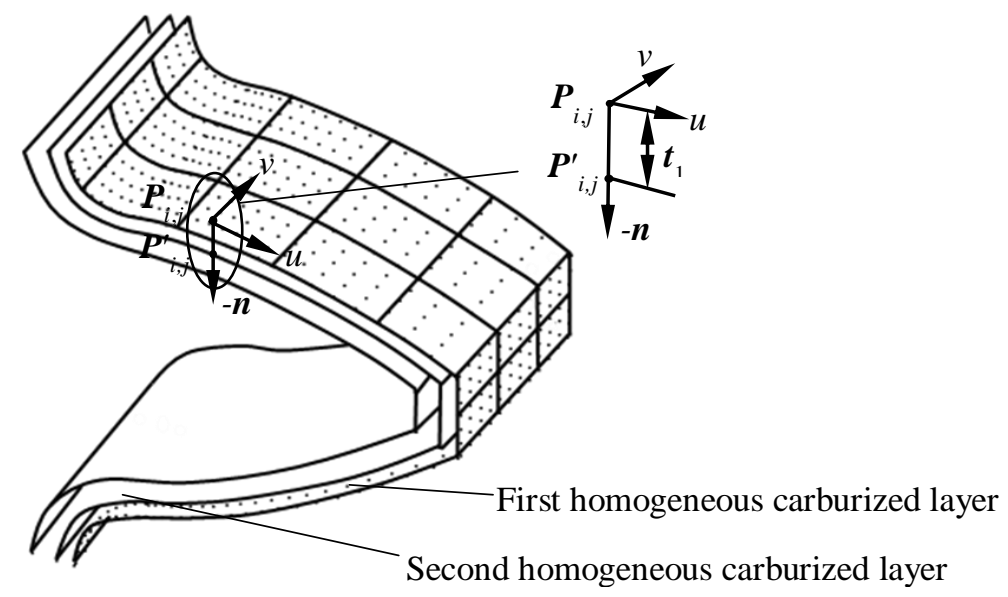

Figure 3: Equidistant surface and homogeneous carburized layer.

\subsection{FEM model of the carburized gear pair}

Under normal circumstances, gear failure generates in the gear tooth and rarely in the part of the hub. The gear hub near the shaft hole is simplified as a rigid cylindrical surface to facilitate the finite element analysis, and the stress and deformation within the rigid cylindrical surface are ignored. The simplified carburized gear entity is divided into several parts to generate a regular FEM model. Fig. 4 shows a half-tooth segmentation diagram, and the tooth is divided into four sections: hub, tooth root, tooth surface, and crest. 


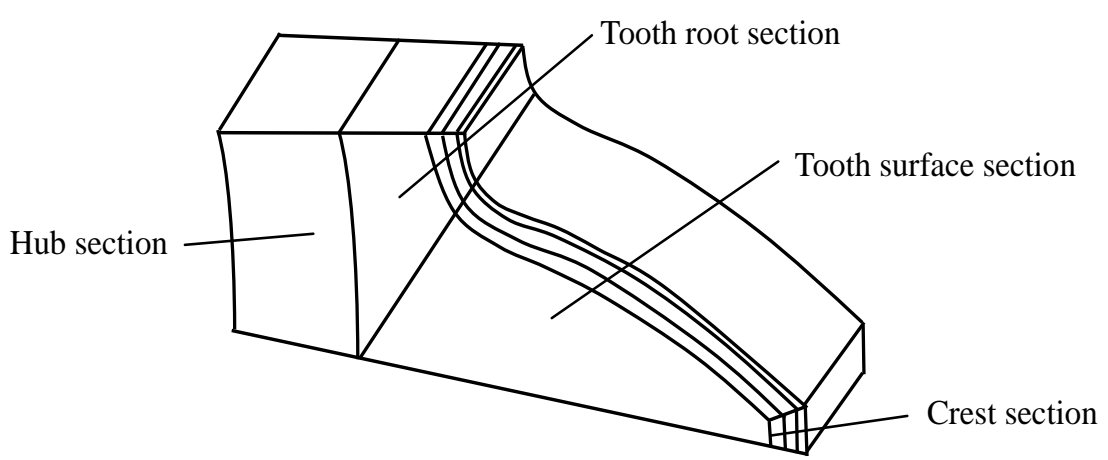

Figure 4: Segmentation diagram of the half tooth.

The point matrix of the tooth profile surface was initially acquired based on the above mentioned method, and an IGES file was generated in accordance with the coordinate sequence of points. Then, the IGES file was imported to general modelling software, and the tooth profile surface was obtained by fitting the point matrix. The use of external programming successfully obtained the equidistant offset surface. In this study, the carburized part was divided into three homogeneous layers, and the entity of the carburized gear was generated by the modelling comments of Boolean operation, rotation, copy, and so on. The elastic modulus of the carburized surface was obtained using a lookup table, and the elastic modulus of the homogeneous carburized layer was obtained using linear interpolation. The type of area element and volume element was initially defined. Then, the gear tooth was divided and meshed. The mesh model of the gear tooth is shown in Fig. 5 a.

The number of teeth is simplified in the case of ensuring a pair of gear tooth meshing completely to reduce the computing time. Spur gear generally requires five pairs of teeth, and the helical gears need seven pairs of teeth. The model of the driven gear is generated in the same way with the driving gear and is assembled without a gap, as shown in Fig. 5 b. The contact pair is established between the two meshing surfaces, and is constrained by setting the element type and key item. The rotational speed is applied to the driving gear, and torque is applied to the driven gear, which sets the load steps to start the solution.

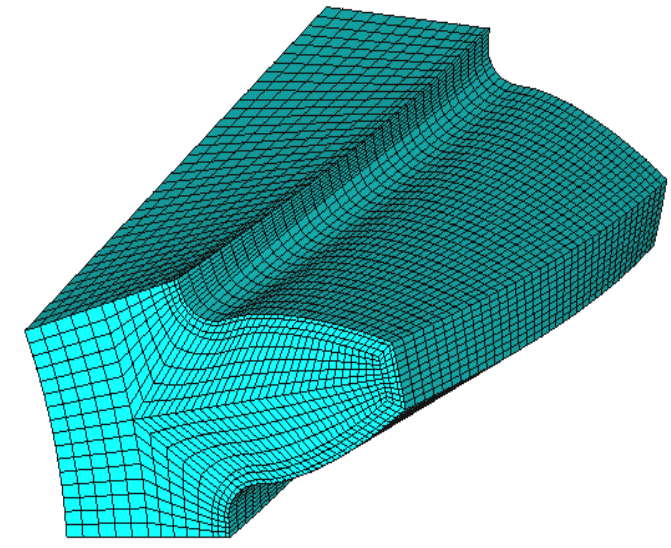

a) Mesh model of the gear tooth

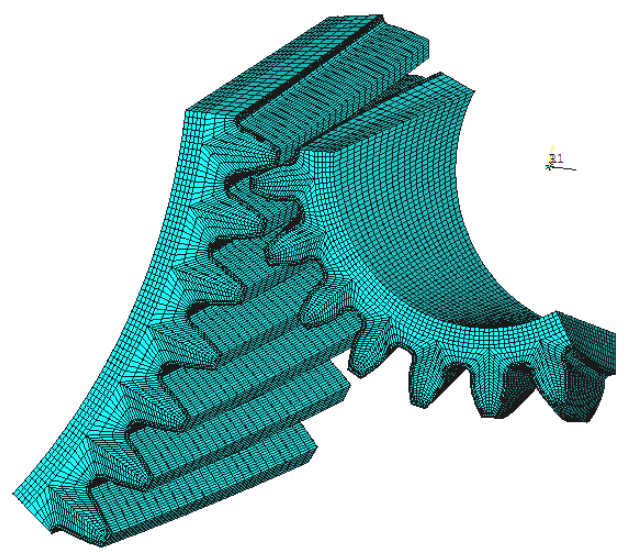

b) Mesh model of the gear pair

Figure 5: Gear mesh model.

\section{SIMULATION ANALYSIS AND DISCUSSION}

In this study, a high-speed helical gear pair in a mine reducer is used for simulation, which can confirm the reliability of the modelling method. Table I lists the basic parameters of the gear pair, where the import power $P$ is $10 \mathrm{~kW}$, the driving gear rotate speed $n_{1}$ is $960 \mathrm{r} / \mathrm{min}$, and the load factor $K_{a}$ is 1.526 . 
Table I: Basic parameters of gear.

\begin{tabular}{|l|l|c|}
\hline \multirow{2}{*}{ Number of teeth } & Driving gear: $z_{1}$ & 21 \\
\cline { 2 - 3 } & Driven gear: $z_{2}$ & 67 \\
\hline Normal modulus: $m$ & 2 \\
\hline \multicolumn{2}{|l|}{ Pressure angle: $\alpha\left(^{\circ}\right)$} & 20 \\
\hline Helix angle: $\beta\left(^{\circ}\right)$ & Driving gear: $x_{1}$ & 14.753 \\
\hline \multirow{2}{*}{ Modification coefficient } & Driven gear: $x_{2}$ & 0 \\
\hline \multirow{2}{*}{ Tooth width $(\mathrm{mm})$} & Driving gear: $B_{1}$ & 35 \\
\cline { 2 - 3 } & Driven gear: $B_{2}$ & 40 \\
\hline \multirow{2}{*}{ Gear material } & Driving gear & $40 \mathrm{Cr}$ \\
\cline { 2 - 3 } & Driven gear & $40 \mathrm{Cr}$ \\
\hline $\begin{array}{l}\text { Depth of the carburized } \\
\text { layer }(\mathrm{mm})\end{array}$ & Driving gear & 0.4 \\
\cline { 2 - 3 } & Driven gear & 0.4 \\
\hline
\end{tabular}

When the finite element model of the gear pair is established and transient analysis is performed, the stress distribution of the carburized gear pair in any position can be obtained at any moment [26, 27]. The time-history (time-hist) curve of the maximum stress can be obtained by reading the maximum contact stress on the surface and the maximum equivalent stress on the tooth root of the carburized gear. Moreover, the maximum shear stress on the surface is calculated, and the worst meshing point and corresponding load step number are obtained. The path along the depth direction, in which its starting point is the node where the maximum shear stress is obtained, is defined, and the shear stress to that path is mapped. Only the first homogeneous layer results are presented because of the space limitation of the thesis. Fig. 6 shows the time-hist curve of the maximum stress. As shown in the Fig. 6, the contact and shear stresses are zero at the beginning of engagement; however, the contact stress increases suddenly for the shock in the fourth pair of the gear teeth and then reduces with rotation. The contact stress increases simultaneously upon entering the single-tooth meshing region. Moreover, the maximum contact stress occurs when the fourth pair of teeth comes into engagement, and the maximum value is $1041.706 \mathrm{MPa}$. The permissible contact stress $[\sigma]_{H}$ is $1546 \mathrm{MPa}$, and the maximum contact stress is in the permissible range of contact fatigue stress, thereby preventing the pitting damage to occur. The shear stress is generated by the extrusion of the contact stress; thus, the positions of the maximum shear and contact stresses are in the same location. The maximum surface shear stress is $388.839 \mathrm{MPa}$. Surface shear stress is still $\neq 0$ after meshing of the fourth pair of the gear teeth due to the influence of residual stress.



Figure 6: Time-hist curve of the maximum stress. 
With the involvement of other teeth, the bending stress on the fourth pair of the gear teeth is $\neq 0$, with or without meshing. The maximum root bending stress of the driving and driven gears are 222.230 MPa and 165.611 MPa, respectively, and they appear in the single-tooth meshing region. The permissible bending stress $[\sigma]_{F}$ is $400 \mathrm{MPa}$, which does not appear during overload breaking.

The stress distribution in different layers changes during engaging due to the properties of heterogeneous material. For the fourth pair of the gear tooth, Figs. $7 \mathrm{a}, 7 \mathrm{~b}, 7 \mathrm{c}$, and $7 \mathrm{~d}$ show equivalent stress distributions from the outer to the inner carburized layer and the body. As shown in Fig. 7, the stress distribution of the gear in different carburized parts is uneven.

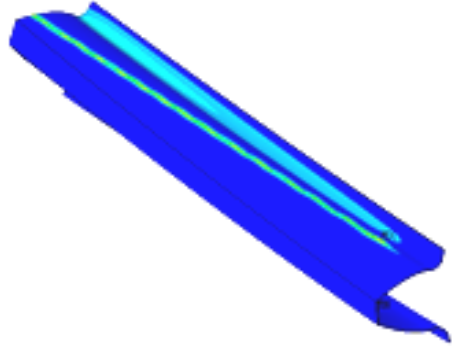

a) Equivalent stress distribution in the outermost layer

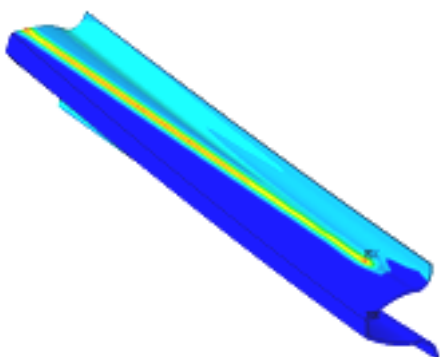

c) Equivalent stress distribution in the transition layer

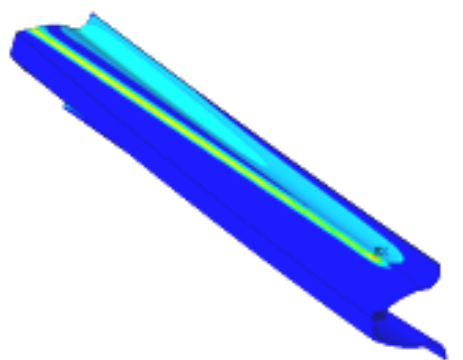

b) Equivalent stress distribution in the middle layer

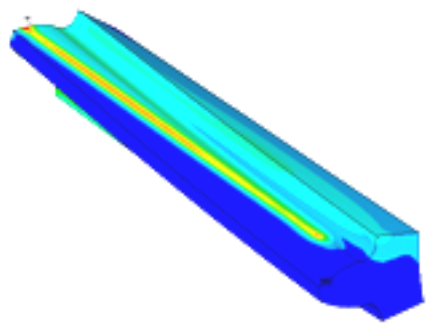

d) Equivalent stress distribution in the body

Figure 7: Equivalent stress distribution in each carburized layer.

Table II shows the maximum stress value in each layer, which appear at different times. The maximum equivalent stress on the tooth surface and root decreases gradually from the outer to inner layers, and the maximum surface shear stress between each layer appears in the middle layer. Moreover, the maximum value is $554.75 \mathrm{MPa}$, and the yield strength $[\sigma]_{s}$ of the material is $985 \mathrm{MPa}$, thus preventing shallow spalling to occur. The shear stress value in the transition layer is $226.553 \mathrm{MPa}$, and the shear strength resistance [ $\tau$ ] of the material is 571 $\mathrm{MPa}$. The ratio of the two stress values does not exceed 0.55 , which does not occur during spalling.

Table II: Maximum stress value in each layer.

\begin{tabular}{|l|c|c|c|c|}
\hline Position & $\begin{array}{c}\text { Outermost } \\
\text { layer }\end{array}$ & $\begin{array}{c}\text { Middle } \\
\text { layer }\end{array}$ & $\begin{array}{c}\text { Transition } \\
\text { layer }\end{array}$ & $\begin{array}{c}\text { Body } \\
\text { section }\end{array}$ \\
\hline Maximum equivalent stress on surface & 890.394 & 592.807 & 301.976 & 233.106 \\
\hline Maximum shear stress on surface & 388.839 & 554.750 & 358.932 & 226.553 \\
\hline Maximum equivalent stress on root & 222.230 & 164.899 & 102.665 & 84.545 \\
\hline
\end{tabular}

The traditional method calculates the strength of gears in the same way with or without carburization. The same parameters are used for gears to illustrate their differences, and carburized gear is regarded as a homogeneous material to perform transient simulation 
analysis. The stress distribution of gears for the two modelling methods is compared by defining the path in depth direction, as shown in Fig. 8. Figs. 8 a and $8 \mathrm{~b}$ present the stress variety trends of shear and equivalent stresses along the depth direction. As shown in Fig. 8, the variety trend of shear stress for stratification modelling increased initially and then decreased, and the maximum value appears below the $0.1 \mathrm{~mm}$ surface. However, the shear stress of the model without stratification decreases with the increase of depth, and the maximum value appears on the gear surface, which is smaller than that for stratification. The variety trends of the equivalent stress of the two modelling methods along the depth direction are similar. The equivalent stress value of non-stratification modelling is smaller than that for stratification.

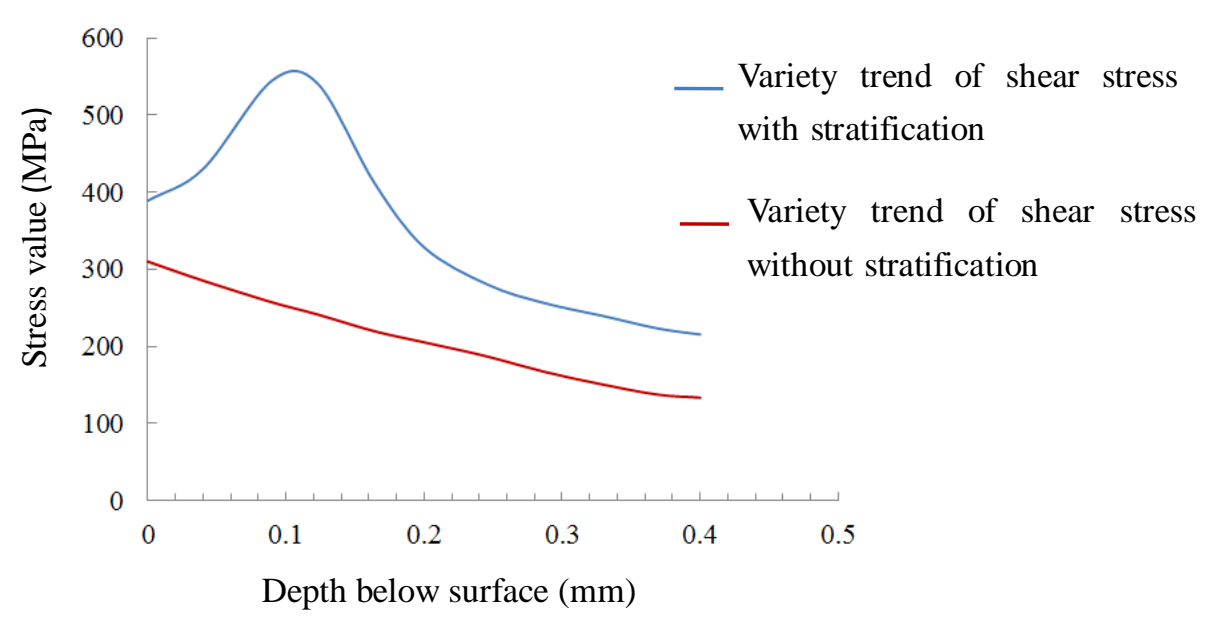

a) Variety trend of shear stress along depth direction

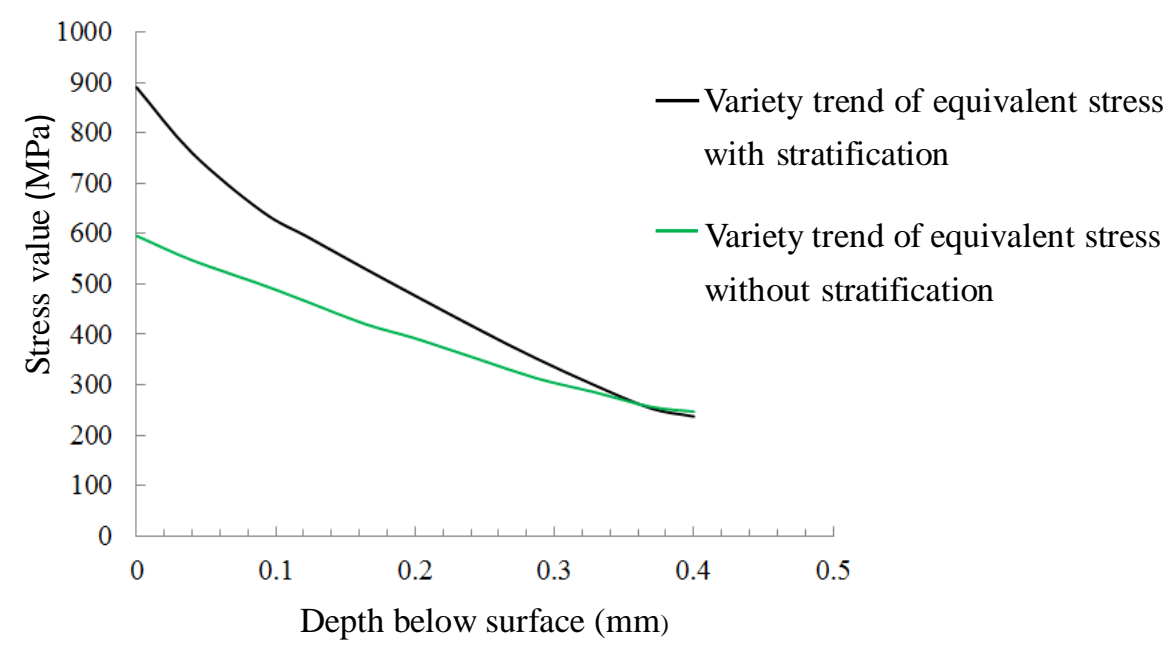

b) Variety trend of equivalent stress along depth direction

Figure 8: Stress variety trend along depth direction.

\section{CONCLUSIONS}

Three kinds of failure forms of gears were analysed theoretically in this study. Given that the carburized layer is a heterogeneous material, a novel method of treating heterogeneous carburized layer as a multilayer homogeneous material was proposed. Then, the specific process of establishing the finite element model of carburized gear pair was studied. Lastly, for a carburized helical gear pair, transient analysis was performed and was compared with the carburized gear modelling without stratification. The following conclusions were obtained:

(1) The extrusion of surface contact stress produces shear stress. The maximum values of surface contact and shear stress appear in the same meshing position of the gear tooth. 
(2) The maximum stress on the surface and tooth root of each carburized layer does not appear simultaneously during meshing. The maximum equivalent stress value decreases along the depth of carburized layer, and the maximum shear stress appears in the middle layer.

(3) The maximum shear stress of the carburized gear with stratification is produced below the surface, whereas the maximum shear stress without stratification appears on the tooth surface. The maximum bending stress varies slightly using the two modelling methods; however, the contact and shear stresses change significantly.

(4) The use of stratification method for carburization can reflect the actual structure more accurately compared with carburized gears treated as homogeneous materials. The stress distribution can be viewed in each layer.

The limitations of existing technology are compensated in this study, and accurate analysis and meshing performance evaluation of carburized gear transmission are achieved. However, considering the computational efficiency, this study has simplified the gear pair model, ignored the influence of weight and inertia, and assembled the gear pair without gap, which can produce errors.

\section{ACKNOWLEDGEMENT}

This work was supported by the National Natural Science Foundation of China (Grant Nos. 51375282 and 51674155), the Special Funds for Cultivation of Taishan Scholars, the Shandong Provincial Natural Science Foundation of China (Grant Nos. ZR2015EM017 and ZR2014EEM021), the Science and Technology Development Program of Shandong Province (Grant No. 2014GGX103043), and the Innovation Foundation for Graduate Students of Shandong University of Science and Technology (Grant No. YC150211).

\section{REFERENCES}

[1] Jedliński, L.; Jonak, J. (2017). A disassembly-free method for evaluation of spiral bevel gear assembly, Mechanical Systems and Signal Processing, Vol. 88, 399-412, doi:10.1016/ j.ymssp.2016.11.005

[2] Walvekar, A. A.; Sadeghi, F. (2017). Rolling contact fatigue of case carburized steels, International Journal of Fatigue, Vol. 95, 264-281, doi:10.1016/j.ijfatigue.2016.11.003

[3] Mohrbacher, H. (2016). Metallurgical concepts for optimized processing and properties of carburizing steel, Advances in Manufacturing, Vol. 4, No. 2, 105-114, doi:10.1007/s40436-016$\underline{0142-9}$

[4] Takemasu, T.; Koide, T.; Shinbutsu, T.; Sasaki, H.; Takeda, Y.; Nishida, S. (2014). Effect of surface rolling on load bearing capacity of pre-alloyed sintered steel gears with different densities, Procedia Engineering, Vol. 81, 334-339, doi:10.1016/j.proeng.2014.10.002

[5] Wang, Y. L.; Xu, S. R.; Hui, Y. L. (2016). Research on laser quenching process of 20CrMnMo gears by finite element method and experiment, The International Journal of Advanced Manufacturing Technology, Vol. 87, No.1, 1013-1021, doi:10.1007/s00170-016-8534-3

[6] Li, X.-Y.; Li, S.-S.; Zeng, Q.-L. (2011). Study on strength of carburized gear for mining gearbox based on dynamics, Journal of China Coal Society, Vol. 36, No. 7, 1227-1231, doi:10.13225/j.cnki.jccs.2011.07.008

[7] Boniardi, M.; D'Errico, F.; Tagliabue, C. (2006). Influence of carburizing and nitriding on failure of gears - A case study, Engineering Failure Analysis, Vol. 13, No. 3, 312-339, doi:10.1016/j.engfailanal.2005.02.021

[8] Rudenko, S. P.; Val'ko, A. L.; Mosunov, E. I. (2012). Structure of carburized layers of transmission gears of power-saturated vehicles, Metal Science and Heat Treatment, Vol. 54, No. 3-4, 189-194, doi:10.1007/s11041-012-9480-9

[9] Yamanaka, M.; Matsushima, Y.; Miwa, S.; Narita, Y.; Inoue, K.; Kawasaki, Y. (2010). Comparison of bending fatigue strength among spur gears manufactured by various methods, Journal of Advanced Mechanical Design, Systems, and Manufacturing, Vol. 4, No. 2, 480-491, doi: $\underline{10.1299 / j a m d s m .4 .480}$ 
[10] Zwolak, J.; Palczak, A. (2016). Effect of gear teeth finishing method on properties of teeth surface layer and its resistance to pitting wear creation, Journal of Central South University, Vol. 23, No. 1, 68-76, doi:10.1007/s11771-016-3050-z

[11] Liu, W. (2014). The failure analysis of the repeat geartooth breakage in a $40 \mathrm{MW}$ steam turbine load gearbox and the butterfly in the carburized case, Engineering Failure Analysis, Vol. 46, 9-17, doi:10.1016/j.engfailanal.2014.07.024

[12] Zhang, J.; Zhang, Q.; Wu, C. H.; Xu, Z. Z.; Lyu, S. K. (2014). Experimental application of pitting formation for $20 \mathrm{MnCr} 5$ carburized gear tooth, International Journal of Precision Engineering and Manufacturing, Vol. 15, No. 5, 899-903, doi:10.1007/s12541-014-0415-9

[13] Kim, N-K.; Bae, K-Y. (2015). Analysis of deformation in the carburizing-quenching heat treatment of helical gears made of SCM415H steel, International Journal of Precision Engineering and Manufacturing, Vol. 16, No. 1, 73-79, doi:10.1007/s12541-015-0009-1

[14] Decroos, K.; Seefeldt, M. (2013). Modeling of distortions after carburization and quenching processes of large gears, Modeling and Simulation in Materials Science and Engineering, Vol. 21, No. 3, Paper 035002, doi:10.1088/0965-0393/21/3/035002

[15] Li, Z. C.; Freborg, A. M.; Hansen, B. D.; Srivatsan, T. S. (2013). Modeling the effect of carburization and quenching on the development of residual stresses and bending fatigue resistance of steel gears, Journal of Materials Engineering and Performance, Vol. 22, No. 3, 664-672, doi:10.1007/s11665-012-0306-0

[16] Sugianto, A.; Narazaki, M.; Kogawara, M.; Kim, S. Y.; Kubota, S. (2010). Distortion analysis of axial contraction of carburized-quenched helical gear, Journal of Materials Engineering and Performance, Vol. 19, No. 2, 194-206, doi:10.1007/s11665-009-9476-9

[17] Sugimoto, T.; Qin, M.; Watanabe, Y. (2006). Computational study of gas quenching on carburizing hypoid ring gear, Berg-und Hüttenmännische Monatshefte, Vol. 151, No. 11, 456461, doi:10.1007/BF03165207

[18] Kim, K.-S. (2014). Characteristic analysis of carburized quenching processes for bevel gear of automobile driving part, Current Nanoscience, Vol. 10, No. 1, 51-55, doi:10.2174/ 1573413709666131111230030

[19] Kim, D.-W.; Cho, H.-H.; Lee, W.-B.; Cho, K. T.; Cho, Y.-G.; Kim, S.-J.; Han, H. N. (2016). A finite element simulation for carburizing heat treatment of automotive gear ring incorporating transformation plasticity, Materials \& Design, Vol. 99, 243-253, doi:10.1016/ j.matdes.2016.03.047

[20] Sharma, V. K.; Walter, G. H.; Breen, D. H. (1979). An analytical approach for establishing case depth requirements in carburized gears, Journal of Heat Treating, Vol. 1, No. 1, 48-57, doi:10.1007/BF02833209

[21] Elkholy, A. (1983). Case depth requirements in carburized gears, Wear, Vol. 88, No. 2, 233-244, doi:10.1016/S0043-1648(83)80011-8

[22] Pu, L. G.; Chen, G. D.; Wu, L. Y. (2008). Design of Machine, $9^{\text {th }}$ edition, Higher Education Press, Beijing (in Chinese)

[23] Gere, J. M.; Goodno, B. J. (2013). Strength of Materials, China Machine Press, Beijing

[24] Ma, H.; Song, R. Z.; Pang, X.; Wen, B. C. (2014). Time-varying mesh stiffness calculation of cracked spur gears, Engineering Failure Analysis, Vol. 44, 179-194, doi:10.1016/ j.engfailanal.2014.05.018

[25] Piegl, L.; Tiller, W. (1997). The NURBS Book, $2^{\text {th }}$ edition, Springer -Verlag, New York

[26] Li, X. Y.; Wang, N. N.; Lv, Y. G.; Zeng, Q. L.; Hidenori, K. (2016). Tooth profile modification and simulation analysis of involute spur gear, International Journal of Simulation Modelling, Vol. 15, No. 4, 649-662, doi:10.2507/IJSIMM15(4)6.358

[27] Dai, Y.; Chen, L. S.; Zhu, X.; Liu, H. (2016). Modelling and simulation of a mining machine excavating seabed massive sulfide deposits, International Journal of Simulation Modelling, Vol. 15, No. 2, 377-387, doi:10.2507/IJSIMM15(2)CO10 